\title{
Temperature and nitrogen nutrition in relation to flowering and fruiting in tomatoes ${ }^{1}$
}

\author{
A. A. Abdalla and K. Verkerk \\ Department of Horticulture, Faculty of Agriculture, University of Khartoum, Sudan \\ Department of Horticulture, Agricultural University, Wageningen, the Netherlands
}

Received 22 September 1969

\begin{abstract}
Summary
Two levels of tissue nitrogen, ' $N$ ' and ' $n$ ', were maintained in tomato plants at a high temperature of $35^{\circ} \mathrm{C}$ day and $25^{\circ} \mathrm{C}$ night and at a normal temperature of $22^{\circ} \mathrm{C}$ day and $18^{\circ} \mathrm{C}$ night by the use of two nutrient solutions comparable in ionic concentration, but one with nitrogen and the other without. Tissue nitrogen was more in plants at the high temperature. Nitrate nitrogen was particularly high at the high temperature, possibly as a result of poor protein synthesis. At the high temperature nitrogen deficiency symptoms appeared in plants with relatively high tissue nitrogen. Plants with less tissue nitrogen at the normal temperature did not show similar symptoms. More tissue nitrogen was associated with more trusses, less flower drop, more fruits set and more fruits harvested.
\end{abstract}

\section{Introduction}

Poor growth and nitrogen deficiency symptoms occur often in tomato fields during August, September and October in the hot arid parts of the Spdan, where the mean daily temperature during these months is $31^{\circ} \mathrm{C}$ with maxima often reaching $40^{\circ} \mathrm{C}$. The tomato vine becomes generally small, with thin elongated branches, and the developing fruits are often sun-burnt. The fruit-carrying capacity of the trusses and the fruit size are reduced. Nitrogen nutrition of tomatoes grown under temperatures optimum for growth and fruiting received considerable attention. Similar work in conditions of high temperatures adverse to growth and fruiting is clearly lacking. Use of nitrogen fertilizers in the early tomato growing in the Sudan and areas with comparable climate is still empirical. It is often thought that in conditions of high temperature frequent applications and large amounts of nitrogen are necessary. Whether these high rates of nitrogen application would have detrimental effects on flowering and fruiting or whether they are necessary is not well known. The validity of the conclusions of Kraus and Kraybill (1918) and Nightingale (1928) in relation to carbohydrate and nitrogen levels and their influence on vine growth and fruiting has not been tested under conditions of high temperature.

The preliminary investigation - described here - is an attempt to define the nitrogen requirement of tomatoes at high temperatures with special reference to flowering

I This article will also be published as Publication 321, Laboratorium voor Tuinbouwplantenteelt, Landbouwhogeschool, Wageningen, the Netherlands. 
and fruiting. Such information will help to guide future nitrogen fertilizer work and practices under adverse conditions of high temperature. The experiment was designed to study the effects of two different levels of tissue nitrogen in plants grown at high temperature and at temperatures normal for tomato growing in the Netherlands.

\section{Materials and methods}

\section{Peat culture}

Seedlings of the tomato cultivar 'Glory' were raised in a glasshouse at about $20^{\circ} \mathrm{C}$. Three weeks old seedlings were transplanted each in a 12 inch plastic pot containing peat and placed on flats also containing peat. The $\mathrm{pH}$ of the peat in the pots, originally 4 , was adjusted to 6.5 by the addition of lime (Dolokal). After transplanting, the plants were divided into two groups. One group was kept in a glasshouse at $35^{\circ} \mathrm{C}$ day and $25^{\circ} \mathrm{C}$ night $(12 \mathrm{~h}+12 \mathrm{~h})$. The other group was kept at $22^{\circ} \mathrm{C}$ day and $18^{\circ} \mathrm{C}$ night temperatures, which are considered normal for tomato growing in the Netherlands. These sets of temperatures are hereafter referred to as 'high' and 'normal'. At each of the two temperatures, the plants were given a nutrient solution with $60 \%$ of the essential ions as nitrate (Steiner, 1961) three times a week, in addition to watering, for a period of three weeks. The plants at both temperatures were then each split into two groups. One group continued to receive the same nutrient solution $(\mathrm{N})$ and for the other group the original nutrient solution was substituted by a solution of comparable ionic concentration, but without nitrogen (n). In this manner two different nitrogen levels of the plant tissue, $\mathrm{N}$ and $\mathrm{n}$, were achieved at both high and normal temperature.

Three weeks later, at the time of fruit set, leaf analyses of the plants for the total and nitrate nitrogen were made. Other data collected included time of appearance of nitrogen deficiency symptoms, fresh weight of vine, counts of flowers, shed flowers, fruits set and fruits developed, all in the first truss. Weights of harvested ripe fruits were determined.

Because of failure of plants to fruit set at the high temperature hand pollinations were made, using fresh pollen from plants growing at the normal temperature. In each plant six fully open flowers were hand-pollinated without emasculation. The styles were long enough to be immersed in the pollen which was then visible on the surface.

\section{Water culture}

Tomato seedlings were raised in perlite. Three weeks old seedlings were transferred to water culture at both high and normal temperatures. The nutrient solution was the same as for peat culture. After 18 days the nutrient solution used was drained and substituted by a nutrient solution with comparable ionic concentration but without nitrogen.

The time to the appearance of the nitrogen deficiency symptoms was observed. Leaf analysis was carried out at the time of the substitution of the nutrient solution and at the time when the deficiency symptoms were evident. Weights of the roots and the vine were recorded at the end of the experiment.

\section{Results and discussion}

Tissue nitrogen data show that temperature affects the total nitrogen and the nitratenitrogen levels in the plant. The plants at the high temperature have a higher level 
Table $I$ Effect of temperature on tissue nitrogen in tomatoes

\begin{tabular}{lcccc}
\hline & \multicolumn{2}{c}{ Tissue nitrogen (\% dry matter) } & & Nitrate nitrogen \\
\cline { 2 - 3 } & total nitrogen & nitrate nitrogen & & total nitrogen \\
High temp., $\mathrm{N}$ & 3.74 & 1.50 & $* 4$ & 0.4 \\
High temp., $\mathrm{n}$ & 3.17 & 0.31 & 0.1 \\
Normal temp., $\mathrm{N}$ & 1.96 & 0.11 & 0.06 \\
Normal temp., $\mathrm{n}$ & 1.30 & 0.02 & \\
\hline
\end{tabular}

of nitrogen than the plants at the normal temperature. The differences in the nitratenitrogen levels between these plants are markedly higher than the differences in the total nitrogen levels. The ratio of the nitrate-nitrogen to the total nitrogen decreases sharply with lower temperature (see Table 1). At the high temperature protein synthesis decreases and consequently less nitrate is consumed resulting in an increased level of nitrate. Banga and Bruyn (1968) found a higher nitrate level in carrot roots grown at higher temperatures and protein production by roots was always higher at the lower temperatures.

Nitrogen deficiency symptoms (yellowing of the lower leaves) appeared first in the normal temperature plants with a low nitrogen level (n) about ten days after the nutrient solution without nitrogen was started. Appearance of deficiency symptoms in plants with a low nitrogen level (n) at the high temperature was delayed about a week. To eliminate any possible influence of peat on nitrogen uptake at the different temperatures, the water culture experiment was conducted. Time required for the appearance of deficiency symptom subsequent to the change of the nutrient solution was the same as in the peat experiment. Furthermore, the pot peat analysis in Table 2 reveals negligible influence of peat on nitrogen uptake. The total nitrogen in percents of dry matter in the high-temperature and normal-temperature plants of the water culture at the time of the change of the nutrient solutions was 3.33 and 2.32, respectively. Later on, when the nitrogen deficiency symptoms were evident, the total nitrogen values dropped to 2.22 and 1.55 for the high and normal temperature plants, respectively. The nitrate nitrogen was not determined. These results follow the same trend obtained in the peat experiment.

Plants at the high temperature (High temp., $n$ ) had more tissue nitrogen than plants at the normall temperature (Normal temp., $N$ ) and yet the former plants developed nitrogen deficiency symptoms earlier than the latter. It appears that plants at the high

Table 2 Pot soil analysis - nitrogen

\begin{tabular}{lcc}
\hline & \multicolumn{2}{c}{ Nitrogen level in peat } \\
\cline { 2 - 3 } & $\begin{array}{c}\text { total nitrogen } \\
(\% \text { dry matter })\end{array}$ & $\begin{array}{c}\text { nitrate nitrogen } \\
(m g / 100 \mathrm{~g} \text { dry matter })\end{array}$ \\
High temp., N & 0.37 & 30 \\
High temp., n & 0.37 & 0 \\
Normal temp., $\mathrm{N}$ & 0.30 & 0 \\
Normal temp., n & 0.38 & 0 \\
\hline
\end{tabular}


Table 3 Effect of temperature and nitrogen nutrition on flower drop, fruit-set, fruit development and fruit weight in the first truss

\begin{tabular}{|c|c|c|c|c|}
\hline & \multicolumn{2}{|c|}{ High temperature } & \multicolumn{2}{|c|}{ Normal temperature } \\
\hline & $N$ & $n$ & $N$ & $n$ \\
\hline Number of flowers & 11.0 & 11.5 & 10.5 & 11.0 \\
\hline Flowers dropped & 3.2 & 5.5 & 1.2 & 4.0 \\
\hline Fruits set & $6.0 !$ & $5.0^{1}$ & 7.5 & 5.2 \\
\hline $\begin{array}{l}\text { Fruits developed } \\
(>20 \mathrm{~g})\end{array}$ & 6.0 & 4.2 & 7.0 & 3.5 \\
\hline Fruit weight \pm S.D. (g) & $47.5 \pm 7.3$ & $27.9 \pm 2.6$ & $81.0 \pm 5.8$ & $52.6 \pm 6.4$ \\
\hline Fruits by vibration & 5.2 & 3.0 & 8.0 & 5.0 \\
\hline
\end{tabular}

1 Six flowers hand-pollinated

temperature contain a high level of nitrogen which is somehow not properly utilized. It may also be that at the high temperature, the critical level of nitrogen below which deficiency symptoms will appear is high. Appearance of deficiency symptoms at high nitrogen levels of the tissue at the high temperature is probably linked to the carbohydrate level and chlorophyll concentration in the leaves, both of which are probably inadequate at such high temperatures. It is therefore suggested that the appearance of the nitrogen deficiency symptoms is highly influenced by temperature and is not simply and quantitatively related to the nitrogen level of the tissue. In order to obtain a plant which is not apparently deficient in nitrogen and will produce good fruits at temperatures higher than optimum, frequent applications and larger amounts of nitrogen may be required. Data collected on flowering and fruiting described below will further substantiate these suggestions.

Table 3 shows that the high temperature increases flower drop. However, in plants with more tissue nitrogen flower drop is less. Flowers at the high temperature failed to set fruit because of lack of pollination resulting from the marked extension of

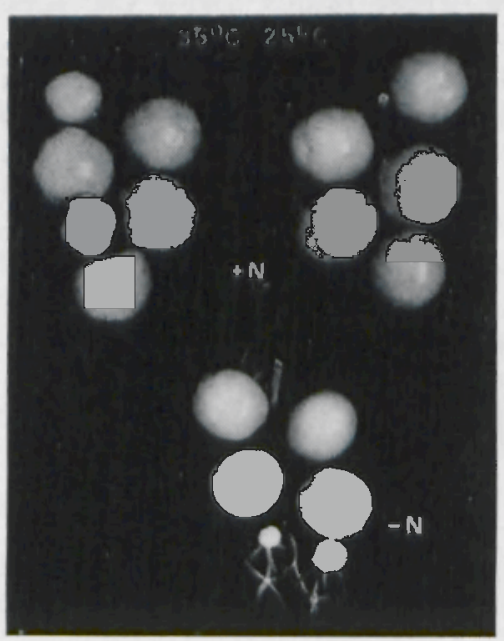

Fig. I Competitive restriction of fruits on the first truss at high temperature $(+N$ and $-N$ represent high and low levels of nitrogen, respectively) 
styles beyond the stamen tube. When equal numbers of flowers were hand-pollinated, plants with a higher nitrogen level set and develop more fruits at the high temperature showing that increased nitrogen level increases the truss carrying capacity.

Fig. 1 shows the marked competative restriction of fruits in the first truss of plants with less nitrogen at the high temperature (marked- $N$ ) indicating a reduced trusscarrying capacity.

The total number of mature developed fruits harvested from two trusses in the normaltemperature plants was 13 and 5 for $N$ and $n$, respectively. It was not possible to get comparable data at the high temperature, because hand pollination was limited to the first truss. However, the number of trusses produced at the high temperature was particularly reduced in the plants with a low nitrogen level (n). Wittwer (1957) reported that high levels of nitrogen $(440 \mathrm{ppm})$ in contrast to low $(55 \mathrm{ppm})$ favour increased flower formation. Garrison (1967) gave results which clearly show that high rates of nitrogen in the field do not contribute to decreased flowering, fruit set and yield. These results are fairly consistent with results obtained at the high temperature used in this study.

Contrary to the generally accepted idea that high nitrogen levels are detrimental to flowering and fruiting in favour of vegetative growth, there is evidence that high nitrogen levels may be necessary for good fruiting in certain environmental conditions, particularly at high temperature.

\section{Acknowledgment}

This work was done during the stay of the senior author as a guest research worker with a Z.W.O. (Netherlands Foundation for the Advancement of Pure Science) Visitors' Grant in the Department of Horticulture at Wageningen. The help of Z.W.O. is hereby gratefully acknowledged. The kind help and co-operation of A. A. Steiner of CPO (Centre for Plant Physiological Research) at Wageningen, who regarded nutrient solutions and water culture techniques, are acknowledged and much appreciated.

\section{References}

Banga, O. \& Bruyn, J. W. de, 1968. Effect of temperature on the balance between protein synthesis and carotenogenesis in the roots of carrot. Euphytica 17: 168-172.

Kraus, E. J. \& Kraybill, H. R., 1918. Vegetation and reproduction with special reference to tomato. Bull. Ore. agric. Exp. Stn 149: 1-90.

Nightingale, G. T., Schermerhorn, L. G. \& Robbins, W. R., 1928. The growth status of the tomato as correlated with organic nitrogen and carbohydrates in roots, stems and leaves. Bull. New Jers. agric. Exp. Stn 461: 1-38.

Steiner, A. A., 1961. A universal method for preparing nutrient solutions of a certain desired composition. Pl. Soil 15: 134-154.

Stephen, A. G., Taylor, G. A. \& Drinkwater, W. O., 1967. The influence of nitrogen nutrition on flowering, fruit set and yield of processing tomatoes. Proc. Am. Soc. hort. Sci. 91: 534-543.

Wittwer, S. H. \& Teubner, F. G., 1957. The effect of temperature and nitrogen nutrition on flower formation in the tomato. Am. J. Bot. 44: 125-129. 